Kastamonu Eğitim Dergisi
$\begin{aligned} & \text { Kastamonu Education Journal } \\ & \text { Mart 2020 Cilt:28 Sayı:2 }\end{aligned}$

\title{
Matematik Laboratuvar Uygulamalarının Sınıf ve Okul Öncesi Öğretmen Adaylarının Matematik Başarı ve Tutumlarına Etkisinin Íncelenmesi
}

\section{The Impact of Mathematics Laboratory Applicatons on Mathematics Achievements and Attutudes of Pre-Service Classroom and Preschool Teachers}

\author{
Cemal INAN ${ }^{1}$, Serdar ERKUŞ ${ }^{2}$
}

\begin{abstract}
Öz
Yapılan bu araştırma, matematik laboratuvar uygulamalarının sınıf ve okul öncesi öğretmen adaylarının matematiğe yönelik tutumlarına, matematik başarılarına ve öğrendiklerini hatırda tutmalarına etkisini incelemeyi amaçlamaktadır. Araştırmada nicel araştırma yöntemlerinden deneysel desenli yöntem kullanılmıştır. Araştırmanın örneklemini 2017 öğrenim yılında Dicle Üniversitesi Sınıf ve Okul Öncesi Öğretmenliği bölümde öğrenim gören 100 öğretmen adayı oluşturmaktadır. Araştırmanın verilerini toplamak için araştırmacılar tarafından geliştirilen başarı testi ve İnan (2007) tarafından geliştirilen tutum ölçeği kullanılmıştır. Başarı testi ve tutum ölçeği hem uygulama öncesi hem de uygulama sonrası sınıf ve okul öncesi öğretmen adaylarına uygulanmıştır. Araştırmada elde edilen veriler SPSS (Statistical Package for the Social Sciences) paket programı kullanılarak analiz edilmiştir. Verilerin analizinde; bağımlı ve bağımsız t-testi kullanılmıştır. Araştırmanın sonuçlarına göre, matematik laboratuvar uygulamalarının sınıf öğretmen adaylarının matematiğe yönelik tutum ve matematik başarılarına olumlu etkisi olduğu söylenebilir. Okul öncesi öğretmen adaylarının ise matematik başarılarında olumlu etkisi olduğu ancak matematiğe yönelik tutumlarında herhangi bir etkisi olmadığı söylenebilir.
\end{abstract}

Anahtar Kelimeler: Matematik, laboratuvar uygulamaları, başarı, tutum

\section{Abstract}

The present study aimed to investigate the impact of mathematics laboratory applications on mathematics attitudes, mathematics achievements and knowledge retention of pre-service classroom and preschool teachers. Experimental design method was used in the study. The study sample included 100 pre-service teachers attending Dicle University 2017 academic year. The achievement test developed by the authors and the attitude scale developed by Inan (2007) were used to collect the study data. The achievement test and attitude scale were applied as both pretest and post-test to pre-service teachers. The data were analyzed with SPSS (Statistical Package for the Social Sciences) software. Data analysis was conducted with dependent and independent t-test. Study results demonstrated that mathematics laboratory applications had a positive impact on mathematics achievement and attitudes. It could be argued that they had a positive impact on mathematics achievement scores of pre-service preschool teachers, however they had no effect on their mathematics attitudes.

Keywords: Mathematics, laboratory applications, achievement, attitude 


\section{Extended Abstract}

Introduction: The analysis of the structure of mathematics would demonstrate that abstract concepts and principles have an significant role. In order for these abstract concepts and principles to be discovered and understood, one has to have certain concrete experiences (Matthews, 1984). Although mathematics and mathematical thinking are related to a significant part of our daily lives, mathematics is considered difficult by all and often difficulties are experienced in teaching mathematics. The difficulty of mathematics stems from the fear and prejudice about mathematics, as well as its structure. In order to alter the position of mathematics, the students should reach the information themselves and conduct activities based on their own observations and experiences, especially starting from elementary and middle school when the foundations of mathematics are laid. Because, each mathematics topic that was not comprehended by the student would lead to larger problems in other topics that the student would learn in the future (Ekinözü \& Şengül, 2007).

It was considered that mathematics labs equipped with current technological devices parallel to technological advances, where the students would feel comfortable, and learn by playing games and utilize the material that would concretize the mathematics course would facilitate learning. The present study was conducted with the experimental method and aimed to respond to the following research questions:

1. Do mathematics laboratory applications have an impact on the attitudes of pre-service classroom teachers towards mathematics, their mathematics achievement, and knowledge retention?

2. Do mathematics laboratory applications have an impact on the attitudes of pre-service preschool teachers towards mathematics, their mathematics achievement, and knowledge retention?

3. Is there a difference between the impact of mathematics laboratory applications on the attitudes of pre-service classroom and preschool teachers towards mathematics, their mathematics achievement, and knowledge retention?

4. Is there a difference between the impact of mathematics laboratory applications on the attitudes of pre-service classroom and preschool teachers towards mathematics, their mathematics achievement, and knowledge retention based on the gender variable?

Method: In the study, experimental method was used. The study sample included 100 pre-service teachers attending Dicle University, Education Faculty, Classroom and Preschool Education Department during the 2017 academic year. The achievement test developed by the authors and the attitude scale developed by inan (2007) were used to collect the study data. The achievement test and attitude scale were applied as both pre-test and post-test to pre-service teachers. The data were analyzed with SPSS (Statistical Package for the Social Sciences) software. Data were analyzed with dependent and independent $t$-test.

Results and Discussion: The findings of the present study which was conducted to investigate the impact of the developed mathematics laboratory applications on the mathematics attitudes, achievements and retention of pre-service teachers, the mean scores of pre-service classroom and pre-school teachers were similar and there was no significant difference between the pretest attitude and pretest achievement scores ( $P>0.05)$. Thus, it could be suggested that the achievement and attitude scores of pre-service classroom and pre-school teachers were similar before the applications were conducted (Table 2). At the end of the study, to determine whether there was a change in the attitudes and achievements of pre-service classroom and preschool teachers, the achievement test and the attitude scale were re-applied to both groups. Based on the data obtained in pre-and post-application analyzes, it was determined that there was a significant difference $(P<0,05)$ between pre-test and post-test achievement and attitude scores of pre-service classroom teachers. There was no significant difference between pre-test and post-test attitude scores of pre-service preschool teachers. However, there was a significant difference between pre-test and post-test achievement scores (Table 3). Based on these results, it can be suggested that laboratory applications had a positive impact on the mathematics attitudes of pre-service classroom teachers and their achievement in the course, and they had a positive impact only on the mathematics achievements of pre-service preschool teachers. This could be due to the fact that preservice classroom teachers take a higher number of mathematics courses when compared to pre-service preschool teachers and they were more motivated for the course.

The achievement test was applied to the same groups one month after the experimental study in order to determine the retention of the impact of mathematics laboratory applications on the mathematics achievement and attitude levels of the preservice classroom and preschool teachers that was discussed until this stage. Analysis of the achievement levels of the groups between the posttest and retention tests demonstrated no significant difference between the achievement levels of the groups (Table 5). Thus, it can be suggested that the groups retained their post-test levels and their acquired knowledge was persistent.

The collected data were analyzed to determine whether there was a difference between the mathematics achievement levels and attitudes of the groups before the experimental process based on gender. It was observed that there was no significant difference between pre-test scores based on gender (Table 6). Thus, it could be suggested that the mathematics achievement and attitude levels of pre-service teachers were similar based on gender before the study. Analysis of post-test achievement and attitudes scores of the groups based on gender demonstrated that there was no significant difference between the achievement and attitude scores based on gender (Table 8). Thus, it could be suggested that the achievement and attitude levels of pre-service teachers were similar based on gender. 
Analysis of pretest and posttest achievement and attitude scores of pre-service teachers based on gender demonstrated that there was a significant difference between the pretest and posttest achievement and attitude scores of male and female pre-service classroom teachers favoring the posttest scores and there was a significant difference between pretest and posttest achievement scores of male and female pre-service preschool teachers favoring the posttest scores. However, there was no significant difference between the pretest and posttest attitude scores of male and female pre-service preschool teachers (Table 9). Thus, it could be suggested that mathematics achievement and attitudes of both female and male pre-service classroom teachers were positively affected by activity-based laboratory courses, in other words, their achievements improved and their attitudes towards mathematics changed in the positive direction. In the group that included pre-service preschool teachers, it could be argued that the activity-based laboratory courses increased the achievements of both female and male group members, however they did not change their attitudes towards mathematics.

In general, there was no significant difference between knowledge retention and mathematics attitudes of pre-service classroom and preschool teachers based on gender ( $P>0.05)$ (Table 10). Thus, it could be suggested that the mathematics comprehension and retention of the mathematics knowledge levels of pre-service teachers were maintained. 


\section{Giriş}

Globalleşen dünyada teknolojideki değişim ve gelişim insanların birbirleri ile etkileşimlerinden çalışma tarzlarına kadar her şeyi etkilemektedir. Bu değişim ve gelişim eğitimin yeniden yapılandırılmasını zorunlu hale getirmektedir (Kellner, 2002). Yaşamları boyunca insanlar çevreleriyle girdikleri etkileşimler sonucu öğrenmenin temelini oluşturan bilgi, beceri, tutum ve değerler gibi kavramları kazanmaktadırlar. Öğrenme genel anlamda, kişinin çevresiyle girdiği etkileşimler sonucu kişide oluşan düşünce, duyuş ve kavrayış değişikliği olarak tanımlanmaktadır. Fakat oluşan bu değişikliğin nasıl meydana geldiğine yönelik çeşitli görüşler bulunmaktadır. Bilimsel kuramlar öğrenmeyi, doğrudan doğruya gözlenemeyen zihinsel bir süreç olarak tanımlamaktadırlar. Piaget ise, insan zihnini kendisine ulaşan her şeye anlam yüklemeye çalışan dinamik bir bilişsel yapı grubu olarak nitelendirmiştir. İnsan zihninin oluşturduğu bu anlam yükleme, kişinin sahip olduğu kültüre, deneyime, kişinin bu süreçteki rolüne ve öğrenmenin gerçekleştiği öğrenmenin doğasına göre farklıık göstermektedir. Bunun yanında öğrenmeyle ilgili çok şey bilinmemesine rağmen, öğrenmenin kişi tarafından kazanıldığı ve önceki öğrenmelerin sonraki öğrenmeleri etkilediği bilinmektedir (Brand, 1990).

Matematiğin yapısı incelediği zaman soyut kavram ve prensiplerin önemli bir yeri tuttuğu görülmektedir. Bu soyut kavram ve prensiplerin keşfedilip anlaşılabilmesi için kişinin bir takım somut deneyimler geçirmesi gerekmektedir (Matthews, 1984). Matematik ve matematiksel düşünme günlük hayatımızın büyük bir bölümünü kapsamasına rağmen, dünyanın her yerinde zor olarak kabul edilmekte ve genellikle öğretiminde de zorluk çekilmektedir. Matematiğin zorluğu, yapısından kaynaklandığı kadar ona karşı oluşan korku ve ön yargılardan da kaynaklanmaktadır. Matematiği bu konumundan kurtarabilmek için özellikle matematiğin temellerinin atıldığı ilkokul ve ortaokul dönemlerinden itibaren öğrencilerin bilgilere kendilerinin ulaşmaları ve kendi gözlem ve deneyimlerine dayalı etkinlikler oluşturmaları gerekmektedir. Çünkü öğrenci tarafından anlaşılamayan her bir matematik konusu, öğrencinin ileride öğreneceği başka matematik konuları için daha büyük problemleri beraberinde getirecektir (Ekinözü \& Şengül, 2007).

Yaşamımızda önemli bir yer tutan matematiğe karşı gelişen ön yargı ve korku sadece ülkemizde özgü bir sorun değildir. Başka ülkelerdeki eğitimciler ve matematikçiler de insanlara matematiği sevdirmenin, matematik öğretimini daha cazip ve eğlenceli hale getirmenin yollarını aramaktadırlar. Ülkemizde var olan matematik öğretiminin asıl sorunu matematiğin yapısından değil, okullarımızda verilen matematik öğretiminden kaynaklanmaktadır. Özellikle de yaşamla kopuk ve kuru bir şekilde verilen öğretim, ölçmede kullanılan klişe yaklaşımlar öğrencilerin başarısını istenilen düzeye ulaşılmasını engellemekte (Umay, 1996), ve bunun sonucunda öğrenciler matematikte başarısız olmaktadırlar (Yenilmez, 2010). Ayrıca daha da önemlisi, bu durum, matematiğe karşı ön yargılı bireyler yetişmesine yol açmaktadır (Umay, 1996).

Matematiğin öğretim şekli geçtiğimiz son on yılda çok tartışılmıştır (Santos-Trigo, 1996). Okullarda öğrencilere verilen matematik öğretimi ile öğrencilerin elde ettikleri bilgi ve beceriler karşılaştıkları problemleri çözmede yetersiz kalmaktadır. Çünkü öğrenciler elde ettikleri bilgi ve becerilerle problemler üzerinde düşünüp çözüm stratejileri geliştirmek yerine, hızlı bir şekilde işlemler ile sonuca ulaşmak istediklerinden bu konuya araştırmacıların yoğunlaşmasına yol açmıştır (Verschaffel ve diğerleri, 1999). Matematiksel kavramlar soyut kavramlar olduğu için bu kavramların bireyin zihninde oluşması gerekmektedir (Pesen, 2005). Bu doğrultuda bakıldığında, matematiksel kavramları soyut kavramlar olmaktan çıkarıp somutlaştırılmasına yardımcı olacak ortamların oluşturulması öğrencilerin öğrenmelerinde önemli bir yer teşkil etmektedir. Alanyazı incelendiğinde matematiğin zor ve soyut olan yapısını daha basite indirgeyip somutlaştırımasına yardımcı olacak özel sınıfların var olduğu görülmektedir. Bu özel sınıflar matematik laboratuvarı olarak adlandırmaktadır (Ersoy, 2006). Igbokwe (2000) matematik laboratuvarlarını, öğrencilerin farklı materyal ve etkinlikleri kullanarak matematik ile ilgili kavramları keşfedip öğrenebileceği ve çeşitli matematik teori ve gerçeklerini ispatlayabileceği yerler olarak tanımlanmıştır. Maschietto ve Trouche (2010) ise matematik laboratuvarlarını, öğrencilerin materyallere kolayca ulaşmalarına imkân sağlayabilecekleri, matematikle ilgili tecrübelerini uygulayabilecekleri, matematikle ilgili bulmacaları çözebilecekleri, oyunlar oynayabilecekleri ve bunların yanında farklı etkinliklere katılabilecekleri materyal olarak zenginleştirilmiş yerler olarak tanımlamışlardır.

Kayhan (2006) yapmış olduğu çalışmasında, bilgilerin somut modellerle temsil edildiği öğrenme ortamlarında küçük yaştaki öğrencilerin daha anlamlı öğrendiğini sonucuna ulaşmıştır. Ayrıca, öğretimde kullanılan bu somut materyaller, öğrencilere açık ve araştırıı ortamlar hazırlar, serbest çalışma fırsatı sunar. Öğrencilere, birçok öğretmenin göremediği çok karışık fikirlerin keşfedilmesi için fırsatlar hazırlarlar (Noss \& Baki, 1996; Arslan, 2003; Tabuk, 2003; Bedir, 2005; Güven \& Karataş, 2005; Birgin \& Tutak, 2006; İnan, 2006; Baki ve diğerleri, 2007; Gürbüz, 2007; Bozkurt \& Akalın, 2010; İnan \& Erkuş, 2017). Bu doğrultuda bakıldığında, öğrencilerin kendilerini rahat 
hissedebilecekleri, oyunlar oynayarak öğrenmeler gerçekleştirebilecekleri, matematik dersini somutlaştırmayı sağlayacak materyalleri kullanılabilecekleri ve teknolojik gelişmelere paralel bir şekilde güncel teknolojik cihazlar ile donatıımış matematik laboratuvarlarının öğrencilerin öğrenmelerini kolaylaştırdığı sonucuna ulaşılabilir. Alan yazı incelendiğinde; Erkan (2006) öğrenmeyi etkileyen belli başlı süreçleri tanıma, algı ve dikkat, bilgiyi kodlama ve depolama, hatırlama ve örgütleme olarak belirtildiğini; Bu süreçlerin hepsinde laboratuvarlarda kullanılan görsel malzemelerin rolü olduğunu vurgulamıştır. Duatepe ve Ubuz (2003) da yapmış oldukları çalışmalarında laboratuvar temelli geometri derslerinin daha eğlenceli, kalıcı, istek ve merak uyandırdığı vurgulamışlardır. Ayrıca yurtdışında da matematik laboratuvar uygulamaları alanında çalışmalar yapılmış ve bu laboratuvar uygulamalarında Singapur, Güney Kore ve Japonya'da başarılı sonuçlar elde edilmiştir (Özahisha \& Öcal, 2004). Yapılan bu çalışma deneysel bir çalışma olup aşağıdaki sorulara yanıt bulmayı amaçlamaktadır.

1. Matematik laboratuvar uygulamalarının sınıf öğretmeni adaylarının matematiğe yönelik tutumlarına, matematik başarılarına ve öğrendiklerini hatırda tutmalarına bir etkisi var mıdır?

2. Matematik laboratuvar uygulamalarının okul öncesi öğretmen adaylarının matematiğe yönelik tutumlarına, matematik başarılarına ve öğrendiklerini hatırda tutmalarına bir etkisi var mıdır?

3. Matematik laboratuvar uygulamalarının sınıf ve okul öncesi öğretmen adaylarının matematiğe yönelik tutumları, matematik başarıları ve öğrendiklerini hatırda tutmaları arasında anlamlı bir farklıık var mıdır?

4. Matematik laboratuvar uygulamalarının cinsiyet değişkenine göre matematiğe yönelik tutumları, matematik başarıları ve öğrendiklerini hatırda tutmaları arasında anlamlı bir farklılık var mıdır?

\section{Yöntem}

Bu araştırma 2017 öğrenim yılında Dicle Üniversitesi Ziya Gökalp Eğitim Fakültesi Temel Eğitim Bölümünde matematik öğretimi dersi alan 50 (Erkek:34; Kadın:16) sınıf öğretmenliği ve 50 (Erkek:29; Kadın: 21) okul öncesi öğretmenliği adaylarından olmak üzere toplamda 100 öğretmen adayı ile çalışılıı̧tır. Bu araştırmada deneysel desen kullanıldığından evren ve örneklem tayinine gidilmemiştir.

\section{Araştırma Modeli}

Sınıf ve okul öncesi öğretmen adaylarının geliştirilen matematik laboratuvar uygulamalarının matematiğe yönelik tutumlarına, matematik başarılarına ve öğrendiklerini hatırda tutmalarına bir etkisinin olup olmadığını araştırmak amacıyla yapılan bu çalışma deneme modelli bir araştırmadır. Deneme modelleri, neden-sonuç ilişkilerini belirlemeye çalışmak amacıyla doğrudan araştırmacının kontrolü altında, gözlenmek istenen verilerin üretildiği araştırma modelidir (Karasar, 2000).

\section{Araştırmanın Deneysel Deseni}

Araştırma, sınıf öğretmenliği bölümünde okuyan 50 öğretmen adayı ve okul öncesi öğretmenliği bölümünde okuyan 50 öğretmen adayı olmak üzere toplam da 100 öğretmen adayı üzerinde yürütülmüştür. İki grupta kendi programlarındaki matematik öğretimi dersi matematik laboratuvarında işlenmiştir.

\section{Tablo 1. Deney Deseninin Açılmış Durumu}

\begin{tabular}{ccccc}
\hline Gruplar & Seçim & Ön Ölçmeler & $\begin{array}{c}\text { Bağımsız Değişkenin } \\
\text { Yeni Düzeyi }\end{array}$ & Son Ölçmeler \\
\hline $\begin{array}{c}\text { Sinıf ve Okul Öncesi } \\
\text { Öğretmen Adayları }\end{array}$ & Rastgele & $\begin{array}{c}\text { Başarı Testi } \\
\text { Tutum Ölçeği }\end{array}$ & Laboratuvar Etkinlikleri & $\begin{array}{c}\text { Başarı Testi } \\
\text { Tutum Ölçeği } \\
\text { Hatırda Tutma }\end{array}$ \\
\hline
\end{tabular}

\section{Veri Toplama Araçlarının Geliştirilmesi}

Gruplarda matematik öğretimi programına paralel olarak yürütülen Hands On Math: Ready to use games and Activities for Grades adlı laboratuvar etkinlikleri haftada dört ders saati olmak üzere sekiz hafta boyunca uygulanmıştır. Araştırmanın verilerini toplamak amacıyla İnan (2007) tarafından geliştirilen matematik tutum ölçeği kullanılmıştır. Tutum ölçeğinin güvenirlik katsayısı 0.917'dir. Öğretmen adaylarının başarılarını ölçmek için ise; Hands On Math: Ready to use games and Activities for Grades adlı laboratuvar etkinlik kitabı kullanılmıştır. Öncelikle ünitenin belirtke tablosu matematik öğretimi ders müfredatına uygun bir şekilde hazırlanmıştır. Söz konusu hedef ve konular arasındaki ilişkiye göre 50 çoktan seçmeli maddeden oluşan bir ön deneme testi hazırlanmıştır. Hazırlanan ön deneme testi iki matematik öğretim üyesinin, ayrıca dil kullanım yoğunluğu açısından da Türkçe eğitimi ana bilim dalı öğretim elemanının incelemesine sunulmuştur. Bu incelemeler neticesinde gerekli düzeltmeler yapılarak test 
yeniden düzenlenmiş, uygun olmayan maddeler testten çıkarılmış ve test 30 maddeye düşürülmüştür. Hazırlanan test bağımsız bir grup olarak aynı ana bilim dalında öğrenim gören 62 sınıf öğretmen adayına uygulanmıştır. Testler incelendiğinde, 4 testin cevaplandırılmadığı görülmüş ve bu 4 test değerlendirmeden çıkarılarak değerlendirme 53 öğretmen adayı üzerinden yapılmıştır. Ön deneme uygulama sonuçlarına göre madde analizi yapılmıştır. Madde analizi sonucunda ayırt edicilik indisleri 0,20'nin altında olan maddeler testten çıkarılmış ve 24 maddeden oluşan başarı testi oluşturulmuştur.

\section{Verilerin Çözümlenmesi}

Araştırmada öğretmen adaylarının deneysel çalışma öncesinde ve sonrasında matematik başarı ve tutumlarını ölçmek amacı ile matematik başarı testi ve tutum ölçeği uygulanmıştır. Deneysel çalışma sonrasında öğrenilenlerin kalıcılığının sağlanıp sağlanmadığını ölçmek için ise başarı testi uygulanmıştır. Elde edilen veriler düzenlendikten sonra tanımlayııı istatistikler, bağımlı ve bağımsız t-testi kullanılarak çözümlenmiştir.

\section{Bulgular}

Sınıf öğretmeni ve okul öncesi öğretmen adaylarının matematiğe yönelik tutumlarını ve matematik başarılarını belirlemek amacı ile yapılan ön tutum ölçeği ve ön başarı testlerinden elde edilen verilere ilişkin aritmetik ortalama, standart sapma ve bağımsız örneklemler için t testi sonuçları tablo 2'de gösterilmiştir.

Tablo 2. Grupların Ön Test Puanlarının Bağımsız Gruplar t-Testi Sonuçları

\begin{tabular}{|c|c|c|c|c|c|c|c|}
\hline & Gruplar & $\mathbf{N}$ & $x$ & ss & sd & $\mathbf{t}$ & $\mathbf{P}$ \\
\hline \multirow{2}{*}{ Tutum Ön } & Sınıf Öğretmeni Adayları & 50 & 3,28 & 0,42 & \multirow{2}{*}{48} & \multirow{2}{*}{0,82} & \multirow{2}{*}{0,41} \\
\hline & Okul Öncesi Öğretmen Adayları & 50 & 3,19 & 0,58 & & & \\
\hline \multirow{2}{*}{ Başarı Ön } & Sınıf Öğretmeni Adayları & 50 & 10,56 & 3,98 & \multirow{2}{*}{48} & \multirow{2}{*}{0,86} & \multirow{2}{*}{0,93} \\
\hline & Okul Öncesi Öğretmen Adayları & 50 & 10,49 & 4,21 & & & \\
\hline
\end{tabular}

Tablo 2 incelendiğinde, grupların ortalamalarının birbirine yakın olduğu, ön tutum ve ön test başarıları arasında anlamlı bir fark olmadığı $(P>0,05)$ görülmektedir. Buna göre öğrencilerin genel olarak matematik başarı ve tutumlarının benzer olduğu söylenebilir.

Sınıf öğretmeni ve okul öncesi öğretmen adaylarının uygulama öncesi ve uygulama sonrası matematiğe yönelik tutumlarını ve matematik başarılarını belirlemek amacı ile yapılan son tutum ölçeği ve son başarı testlerinden elde edilen verilere ilişkin aritmetik ortalama, standart sapma ve bağımlı örneklemler için t testi sonuçları tablo $3^{\prime}$ te gösterilmiştir.

Tablo 3. Grupların Ön Test-Son Test ve Ön Tutum-Son Tutum puanlarına ilişkin Bağımlı Gruplar t- Testi Sonuçları

\begin{tabular}{|c|c|c|c|c|c|c|c|}
\hline Gruplar & & $\mathbf{N}$ & $\mathbf{x}$ & Ss & sd & $\mathbf{t}$ & $\mathbf{P}$ \\
\hline \multirow{4}{*}{ Sınıf Öğretmeni Adayları } & Tutum Ön & 50 & 3,28 & 0,42 & \multirow{2}{*}{49} & \multirow{2}{*}{$-9,71$} & \multirow{2}{*}{0,00} \\
\hline & Tutum Son & 50 & 4,08 & $-0,41$ & & & \\
\hline & Başarı Ön & 50 & 10,56 & 3,98 & \multirow{2}{*}{49} & \multirow{2}{*}{$-18,25$} & \multirow{2}{*}{0,00} \\
\hline & Başarı Son & 50 & 21,96 & 4,16 & & & \\
\hline \multirow{4}{*}{$\begin{array}{l}\text { Okul Öncesi Öğretmen } \\
\text { Adayları }\end{array}$} & Tutum Ön & 50 & 3,19 & 0,58 & \multirow{2}{*}{49} & \multirow{2}{*}{$-4,59$} & \multirow{2}{*}{0,05} \\
\hline & Tutum Son & 50 & 3,97 & 0,03 & & & \\
\hline & Başarı Ön & 50 & 10,49 & 4,21 & \multirow{2}{*}{49} & \multirow{2}{*}{$-6,53$} & \multirow{2}{*}{0,00} \\
\hline & Başarı Son & 50 & 15,51 & 3,84 & & & \\
\hline
\end{tabular}

Tablo 3 incelendiğinde, sınıf öğretmeni adayları ön tutum ve son tutum, başarı ön test ve son testler arasında anlamlı fark olduğu $(P<0,05)$ görülmektedir. Okul öncesi öğretmen adaylarında ise ön tutum ve son tutum arasında anlamlı bir fark olmadığı, fakat başarı ön test ile başarı son test arasında anlamlı fark olduğu görülmektedir.

Sınıf öğretmeni ve okul öncesi öğretmen adaylarının matematiğe yönelik tutumlarını ve matematik başarılarını belirlemek amacı ile yapılan son tutum ölçeği ve son başarı testlerinden elde edilen verilere ilişkin aritmetik ortalama, standart sapma ve bağımsız örneklemler için $t$ testi sonuçları tablo 4 'te gösterilmiştir. 
Tablo 4. Grupların Son Testler Arasındaki Bağımsız Gruplar t- Testi Sonuçları

\begin{tabular}{|c|c|c|c|c|c|c|c|}
\hline & Grup & $\mathbf{N}$ & $X$ & SS & sd & $\mathbf{t}$ & $\mathbf{P}$ \\
\hline \multirow{2}{*}{ Tutum Son } & Sınıf Öğretmeni Adayları & 50 & 4,08 & 0,41 & \multirow{2}{*}{98} & \multirow{2}{*}{7,44} & \multirow{2}{*}{0,00} \\
\hline & Okul Öncesi Öğretmen Adayları & 50 & 3,37 & 0,53 & & & \\
\hline \multirow{2}{*}{ Başarı Son } & Sınıf Öğretmeni Adayları & 50 & 21,96 & 4,16 & \multirow{2}{*}{98} & \multirow{2}{*}{8,09} & \multirow{2}{*}{0,00} \\
\hline & Okul Öncesi Öğretmen Adayları & 50 & 15,51 & 3,84 & & & \\
\hline
\end{tabular}

Tablo 4 incelendiğinde son testler arasında sınıf öğretmeni adayları lehine anlamlı bir farklılık olduğu $(P<0,05)$ görülmektedir. Sınıf öğretmeni ve okul öncesi öğretmen adaylarının uygulama sonrası matematik başarılarını ve öğrendiklerini hatırda tutmaya ait son başarı ve öğrendiklerini hatırda tutma testlerinden elde edilen verilere ilişkin aritmetik ortalama, standart sapma ve bağımsız örneklemler için t testi sonuçları tablo 5 'de gösterilmiştir.

Tablo 5. Gruplarda Son Testler ve Hatırda Tutma Arasındaki Bağımlı Gruplar t-Testi

\begin{tabular}{|c|c|c|c|c|c|c|c|}
\hline Gruplar & & $\mathbf{N}$ & $x$ & ss & sd & $\mathbf{t}$ & $\mathbf{P}$ \\
\hline \multirow{2}{*}{ Sınıf Öğretmeni Adayları } & Başarı Son & 50 & 21,96 & 4,16 & \multirow{2}{*}{48} & \multirow{2}{*}{0,64} & \multirow{2}{*}{0,52} \\
\hline & Başarı Hatırda Tutma & 50 & 21,50 & 4,06 & & & \\
\hline \multirow{2}{*}{ Okul Öncesi ÖğretmenAdayları } & Başarı Son & 50 & 15,51 & 3,84 & \multirow{2}{*}{48} & \multirow{2}{*}{0,49} & \multirow{2}{*}{0,62} \\
\hline & Başarı Hatırda Tutma & 50 & 15,20 & 3,54 & & & \\
\hline
\end{tabular}

Tablo 5 incelendiğinde son testler ve hatırda tutma testleri arasında; başarıları bakımından anlamlı bir farklılık olmadığı $(P>0,05)$ görülmektedir.

Sınıf öğretmeni ve okul öncesi öğretmen adaylarının cinsiyet değişkenine göre matematiğe yönelik tutumlarını ve matematik başarılarını belirlemek amacı ile yapılan ön tutum ölçeği ve ön başarı testlerinden elde edilen verilere ilişkin aritmetik ortalama, standart sapma ve bağımsız örneklemler için t testi sonuçları tablo 6'da gösterilmiştir.

Tablo 6. Cinsiyete Göre Ön Testler Arasındaki Bağımsız Gruplar t- Testi Sonucu

\begin{tabular}{|c|c|c|c|c|c|c|c|c|}
\hline Cinsiyet & & Grup & $\mathbf{N}$ & $\mathrm{x}$ & Ss & sd & $\mathbf{t}$ & $\mathbf{P}$ \\
\hline \multirow{4}{*}{ Erkek } & \multirow{2}{*}{ Tutum Ön } & Sınıf Öğretmeni Adayları & 29 & 3,24 & 0,31 & \multirow{2}{*}{61} & \multirow{2}{*}{0,29} & \multirow{2}{*}{0,76} \\
\hline & & Okul Öncesi Öğretmen Adayları & 34 & 3,21 & 0,61 & & & \\
\hline & \multirow{2}{*}{ Başarı Ön } & Sınıf Öğretmeni Adayları & 29 & 10,14 & 3,85 & \multirow{2}{*}{61} & \multirow{2}{*}{$-0,44$} & \multirow{2}{*}{0,66} \\
\hline & & Okul Öncesi Öğretmen Adayları & 34 & 10,59 & 4,17 & & & \\
\hline \multirow{4}{*}{ Kadın } & \multirow{2}{*}{ Tutum Ön } & Sınıf Öğretmeni Adayları & 21 & 3,32 & 0,54 & \multirow{2}{*}{35} & \multirow{2}{*}{$-0,87$} & \multirow{2}{*}{0,38} \\
\hline & & Okul Öncesi Öğretmen Adayları & 16 & 3,17 & 0,53 & & & \\
\hline & \multirow{2}{*}{ Başarı Ön } & Sınıf Öğretmeni Adayları & 21 & 11,14 & 4,17 & \multirow{2}{*}{35} & \multirow{2}{*}{$-0,60$} & \multirow{2}{*}{0,54} \\
\hline & & Okul Öncesi Öğretmen Adayları & 16 & 10,29 & 4,42 & & & \\
\hline
\end{tabular}

Tablo 6 incelendiğinde cinsiyete göre genel olarak ön testleri arasında tutum ve başarı arasında anlamlı bir fark olmadığı $(P>0,05)$, bu durumda başlangıçta iki grubun da cinsiyete göre benzer başarı ve tutuma sahip oldukları söylenebilir.

Sını öğretmeni ve okul öncesi öğretmen adaylarının ayrı ayrı cinsiyete göre uygulama öncesi matematiğe yönelik tutumlarını ve matematik başarılarını belirlemek amacı ile yapılan ön tutum ölçeği ve ön başarı testlerinden elde edilen verilere ilişkin aritmetik ortalama, standart sapma ve bağımlı örneklemler için t testi sonuçları tablo 7'de gösterilmiştir.

Tablo 7. Grupların Cinsiyete Göre Ön Testler Arasındaki Bağımsız Gruplar t- Testi

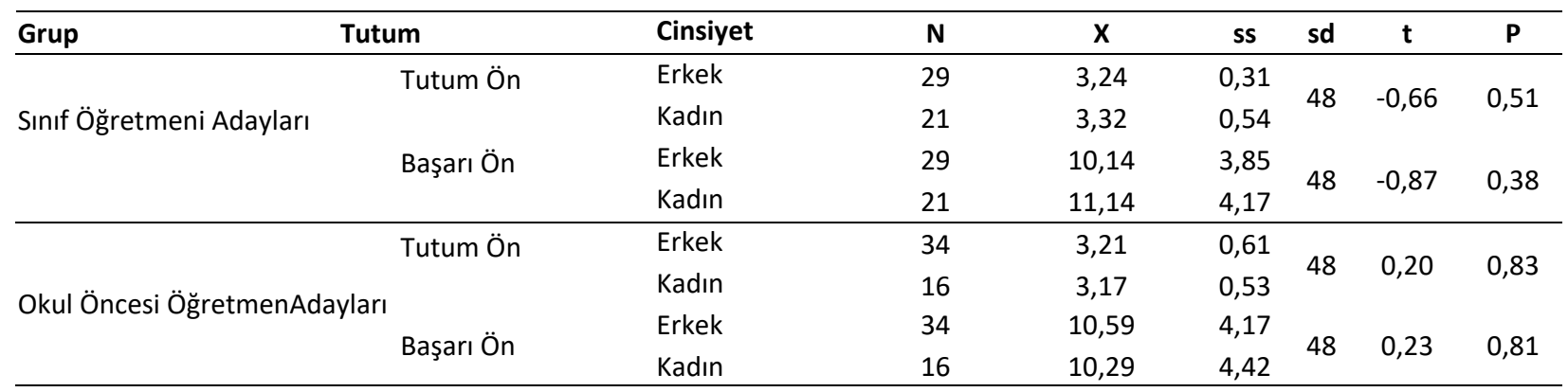

Tablo 7 incelendiğinde gruplarında cinsiyete göre tutum ve başarıları açısından anlamlı bir fark olmadığı $(P>0,05)$ gözlenmiştir. Bu sonuca göre gruplardaki öğrencilerin çalışma öncesinde denk başarı ve matematiğe karşı bezer tutuma sahip oldukları söylenebilir 
Sınıf öğretmeni ve okul öncesi öğretmen adaylarının ayrı ayrı cinsiyete göre uygulama sonrası matematiğe yönelik tutumlarını ve matematik başarılarını belirlemek amacı ile yapılan son tutum ölçeği ve son başarı testlerinden elde edilen verilere ilişkin aritmetik ortalama, standart sapma ve bağımlı örneklemler için t testi sonuçları tablo 8'de gösterilmiştir.

Tablo 8. Grupların Cinsiyete Göre Son Testler Arasındaki Bağımsız Gruplar t- Testi

\begin{tabular}{|c|c|c|c|c|c|c|c|c|}
\hline Grup & Tutum & Cinsiyet & $\mathbf{N}$ & $x$ & Ss & sd & $t$ & $p$ \\
\hline \multirow{4}{*}{$\begin{array}{l}\text { Sınıf Öğretmeni } \\
\text { Adayları }\end{array}$} & \multirow{2}{*}{ Tutum Son } & Erkek & 29 & 4,02 & 0,46 & \multirow{2}{*}{48} & \multirow{2}{*}{$-1,24$} & \multirow{2}{*}{0,21} \\
\hline & & Kadın & 21 & 4,17 & 0,33 & & & \\
\hline & \multirow{2}{*}{ Başarı Son } & Erkek & 29 & 21,24 & 5,11 & \multirow{2}{*}{48} & \multirow{2}{*}{$-1,45$} & \multirow{2}{*}{0,15} \\
\hline & & Kadın & 21 & 22,95 & 2,12 & & & \\
\hline \multirow{4}{*}{$\begin{array}{l}\text { Okul Öncesi } \\
\text { Öğretmen Adayları }\end{array}$} & \multirow{2}{*}{ Tutum Son } & Erkek & 34 & 3,49 & 0,44 & \multirow{2}{*}{48} & \multirow{2}{*}{2,42} & \multirow{2}{*}{0,19} \\
\hline & & Kadın & 16 & 3,12 & 0,61 & & & \\
\hline & \multirow{2}{*}{ Başarı Son } & Erkek & 34 & 15,94 & 3,70 & \multirow{2}{*}{48} & \multirow{2}{*}{1,13} & \multirow{2}{*}{0,26} \\
\hline & & Kadın & 16 & 14,65 & 4,07 & & & \\
\hline
\end{tabular}

Tablo 8 incelendiğinde, gruplarda son testler arasında cinsiyet temelinde anlamlı bir fark olmadığı $(P>0,05)$, bu durumda iki grupta cinsiyete göre benzer tutuma sahip olduğu gözlenmektedir.

Sınıf öğretmeni ve okul öncesi öğretmen adaylarının ayrı ayrı cinsiyete göre uygulama öncesi ve uygulama sonrası matematiğe yönelik tutumlarını ve matematik başarılarını belirlemek amacı ile yapılan ön tutum-son tutum ölçeği ve ön başarı-son başarı testlerinden elde edilen verilere ilişkin aritmetik ortalama, standart sapma ve bağımlı örneklemler için t testi sonuçları tablo 9'da gösterilmiştir.

Tablo 9. Grupların Cinsiyete Göre Ön Test ve Son Testler Arasındaki Bağımlı Gruplar t- Testi

\begin{tabular}{|c|c|c|c|c|c|c|c|c|}
\hline Grup & Cinsiyet & Tutum/Başarı & $\mathbf{N}$ & $x$ & Ss & sd & $\mathbf{t}$ & $\mathbf{p}$ \\
\hline \multirow{8}{*}{$\pm \frac{\frac{1}{\frac{\pi}{d}}}{\frac{\pi}{0}}$} & \multirow{4}{*}{ Erkek } & Tutum Ön & 29 & 3,24 & 0,31 & \multirow{2}{*}{28} & \multirow{2}{*}{$-7,34$} & \multirow[t]{2}{*}{0,00} \\
\hline & & Tutum Son & 29 & 4,02 & 0,46 & & & \\
\hline & & Başarı Ön & 29 & 10,14 & 3,85 & \multirow{2}{*}{28} & \multirow{2}{*}{$-11,97$} & \multirow[t]{2}{*}{0,00} \\
\hline & & Başarı Son & 29 & 21,24 & 5,11 & & & \\
\hline & \multirow{4}{*}{ Kız } & Tutum Ön & 21 & 3,32 & 0,54 & \multirow{2}{*}{20} & \multirow{2}{*}{$-6,23$} & \multirow{2}{*}{0,00} \\
\hline & & Tutum Son & 21 & 4,17 & 0,33 & & & \\
\hline & & Başarı Ön & 21 & 11.14 & 4.17 & \multirow{2}{*}{20} & \multirow{2}{*}{-15.29} & \multirow{2}{*}{0,00} \\
\hline & & Başarı Son & 21 & 22.95 & 2.01 & & & \\
\hline \multirow{8}{*}{ 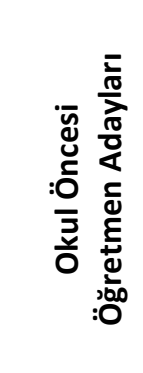 } & & Tutum Ön & 34 & 3,21 & 0,61 & \multirow{2}{*}{33} & \multirow{2}{*}{$-2,29$} & \multirow{2}{*}{0,07} \\
\hline & Erkek & Tutum Son & 34 & 3,49 & 0,44 & & & \\
\hline & & Başarı Ön & 34 & 10,59 & 4,17 & \multirow{2}{*}{33} & \multirow{2}{*}{$-5,27$} & \multirow{2}{*}{0,00} \\
\hline & & Başarı Son & 34 & 15,94 & 3,70 & & & \\
\hline & & Tutum Ön & 17 & 3,17 & 0,53 & \multirow{2}{*}{16} & & \multirow[t]{2}{*}{0,82} \\
\hline & \multirow[t]{3}{*}{ Kız } & Tutum Son & 17 & 3,12 & 0,61 & & 0,22 & \\
\hline & & Başarı Ön & 17 & 10,29 & 4,42 & \multirow{2}{*}{16} & \multirow{2}{*}{$-3,90$} & \multirow{2}{*}{0,00} \\
\hline & & Başarı Son & 17 & 14,65 & 4,07 & & & \\
\hline
\end{tabular}

Tablo 9 incelendiğinde; okul öncesi öğretmenliği bölümündeki kız öğretmen adayların ön ve son tutum puanları hariç diğer gruplarının ön test- son testleri ve ön tutum- son tutum puanları arasında cinsiyete göre anlamlı fark olduğu gözlenmektedir $(p<0.05)$.

Sınıf öğretmeni ve okul öncesi öğretmen adaylarının cinsiyet değişkenine göre başarı son testinden ve hatırda tutma testinden elde edilen verilere ilişkin aritmetik ortalama, standart sapma ve bağımlı örneklemler için t testi sonuçları tablo 10’ da gösterilmiştir. 
Tablo 10. Iki Grubun Ayrı Ayrı Cinsiyet Temelinde Son Test ve Hatırda Tutma Testlerinin Karşılaştırılması Bağımlı Gruplar t-Testi

\begin{tabular}{|c|c|c|c|c|c|c|c|c|}
\hline Grup & & & $\mathbf{N}$ & $\mathbf{x}$ & ss & sd & $\mathbf{t}$ & $\mathbf{p}$ \\
\hline \multirow{8}{*}{ 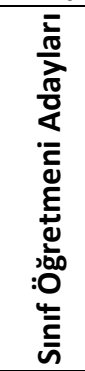 } & Erkek & Başarı Son & 16 & 20.94 & 5.77 & \multirow{2}{*}{15} & \multirow{2}{*}{-0.34} & \multirow{2}{*}{0.73} \\
\hline & 1 & Başarı Hatırda Tut. & 16 & 21.50 & 2.55 & & & \\
\hline & KIz & Başarı Son & 9 & 21.67 & 2.12 & \multirow{2}{*}{8} & \multirow{2}{*}{-0.21} & \multirow{2}{*}{0.83} \\
\hline & 2 & Başarı Hatırda Tut. & 9 & 21.89 & 1.90 & & & \\
\hline & Erkek & Başarı Son & 13 & 21.62 & 4.36 & \multirow{2}{*}{12} & \multirow{2}{*}{0.47} & \multirow{2}{*}{0.64} \\
\hline & 1 & Başarı Hatırda Tut. & 13 & 21.38 & 5.37 & & & \\
\hline & Kız & Başarı Son & 12 & 23.92 & 1.31 & \multirow{2}{*}{11} & \multirow{2}{*}{1.49} & \multirow{2}{*}{0.16} \\
\hline & 2 & Başarı Hatırda Tut. & 12 & 21.33 & 5.49 & & & \\
\hline \multirow{8}{*}{ 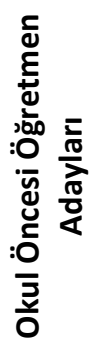 } & Erkek & Başarı Son & 17 & 15.41 & 3.14 & \multirow{2}{*}{16} & \multirow{2}{*}{1.04} & \multirow{2}{*}{0.31} \\
\hline & 1 & Başarı Hatırda Tut. & 17 & 14.41 & 3.48 & & & \\
\hline & $\mathrm{K} 1 \mathrm{Z}$ & Başarı Son & 8 & 13.75 & 4.06 & \multirow{2}{*}{7} & \multirow{2}{*}{0.28} & \multirow{2}{*}{0.78} \\
\hline & 2 & Başarı Hatırda Tut. & 8 & 13.38 & 3.33 & & & \\
\hline & Erkek & Başarı Son & 17 & 16.47 & 4.23 & \multirow{2}{*}{16} & \multirow{2}{*}{0.34} & \multirow{2}{*}{0.73} \\
\hline & 1 & Başarı Hatırda Tut. & 17 & 16.12 & 3.05 & & & \\
\hline & KIz & Başarı Son & 9 & 15.44 & 4.15 & \multirow{2}{*}{8} & \multirow{2}{*}{-0.49} & \multirow{2}{*}{0.63} \\
\hline & 2 & Başarı Hatırda Tut. & 9 & 16.56 & 4.15 & & & \\
\hline
\end{tabular}

Tablo 10 incelendiğinde; cinsiyet temelinde son test ve hatırda tutma testleri arasında anlamlı fark olmadığı gözlenmektedir $(P>0,05)$.

\section{Sonuç}

Geliştirilen matematik laboratuvar uygulamalarının sınıf ve okul öncesi öğretmen adaylarının matematiğe yönelik tutumlarına, matematik başarılarına ve öğrendiklerini hatırda tutmalarına etkisini araştırmak amacıyla yapılan bu araştırmanın verilerinden elde edilen sonuçlara göre, sınıf ve okul öncesi öğretmen adaylarının ortalama puanlarının birbirine yakın olduğu, ön tutum ve ön test başarıları arasında anlamlı bir farklıı̆̆ın olmadığı görülmüştür $(P>0,05)$. Bu sonuca göre, sınıf ve okul öncesi öğretmen adaylarının uygulama öncesindeki başarı ve tutumlarının birbirine benzer olduğu söylenebilir (Tablo 2). Uygulama sonunda sınıf ve okul öncesi öğretmen adaylarının matematik başarılarında ve matematiğe karşı tutumlarında bir değişiklik olup olmadığını belirlemek amacıyla, başarı testi ile tutum ölçeği iki gruba tekrar uygulanmıştır. Uygulama öncesi ve uygulama sonrası analizlerden elde edilen verilere göre, sınıf öğretmeni adaylarının ön tutum ve son tutum, başarı ön test ve son test puanları arasında anlamlı bir farklılığın olduğu $(P<0,05)$ görülmüştür. Okul öncesi öğretmen adaylarının ise, ön tutum ve son tutum puanları arasında anlamlı bir farklıığın olmadığı; fakat başarı ön test ile başarı son test puanları arasında anlamlı bir farklılı̆ın olduğu görülmüştür (Tablo 3). Bu sonuçlara göre, laboratuvar uygulamalarının sınıf öğretmeni adaylarının matematiğe karşı tutum ve dersteki başarılarına olumlu etkisi olduğu ve okul öncesi öğretmen adaylarının ise, sadece matematiğe karşı dersteki başarılarına olumlu etkisi olduğu söylenebilir. Bu sonucun nedeni olarak da, sınıf öğretmeni adaylarının okul öncesi öğretmen adaylarına oranla daha fazla matematik dersi almaları ve derse karşı motivasyonların daha fazla olması gösterilebilir. Literatür incelendiğinde; Srinivasa (1978) da matematik öğretiminde laboratuarların önemini araştırdığı çalışmasında laboratuvarların öğrenci başarısını artırdığı sonucuna ulaşmıştır. Agwagah (1997) da matematik laboratuvarı yaklaşımını inceleyen bir durum analizi yapmış ve bu durum analizi çalışmasında matematik laboratuvarı uygulamalarının öğrenci başarısını artırdığı sonucuna ulaşmıştır. Ogunkunle (2000) de okullarda matematik öğretiminde laboratuar uygulamalarının öğrenci başarısını artırdığı sonucuna varmıştır. Okigbo ve Abigail (2008) de matematik öğretiminde matematik laboratuvarlarının kullanılmasının öğrenci başarısına etkisini araştırmış ve bu araştırmalarında matematik laboratuvarlarının öğrenci başarısını artırdığı sonuna ulaşmışlardır. James (2016) de yapmış olduğu çalışmasında matematik labaratuvarlarının öğrenci başarısını ve öğrencilerin matematiğe yönelik tutumlarını olumlu yönde artırdığı sonucuna ulaşmıştır.

Geliştirilen matematik laboratuvar uygulamalarının sınıf ve okul öncesi öğretmen adaylarının matematik dersindeki başarılarının kalııılığını belirlemek amacı ile deney çalışmasından bir ay sonra başarı testi aynı gruplara tekrar uygulanmıştır. Grupların son testleri ile hatırda tutma testleri arasındaki başarı durumları incelendiğinde; grupların başarıları arasında anlamlı bir farklılığın olmadığı görülmüştür (Tablo 5). Bu sonuca göre, grupların deney sonrası düzeylerini korudukları ve öğrendikleri bilgilerin kalıcılı̆ının sağlandığı söylenebilir. 
Cinsiyet değişkenine göre, grupların kendi içinde deneysel çalışma başlamadan önce matematik başarıları ve matematiğe karşı tutumlarında bir farklıı̆̆ın olup olmadığını belirlemek için elde edilen veriler incelenmiştir. Ön test puanları arasında cinsiyete göre anlamlı bir farklılığın olmadığı görülmüştür (Tablo 6). Bu sonuca göre, deneysel çalışma öncesinde öğretmen adaylarının matematik dersindeki başarıları bakımından denk ve tutum bakımından da benzer olduğu söylenebilir. Grupların cinsiyet değişkenine göre, son başarı ve tutumları karşılaştıııldığında, başarı ve tutum bakımından aralarında anlamlı bir farklılığın oluşmadığı görülmüştür (Tablo 8). Bu sonuca göre, gruplarındaki öğretmen adaylarının deney sonrası başarı durumlarının denk ve tutum bakımından da benzer oldukları söylenebilir. Literatür incelendiğinde; aynı şekilde Okigbo ve Abigail (2008) de yapmış olduğu çalışmalarında matematik öğretiminde matematik laboratuvarlarının kullanılmasının öğrenci başarısına etkisini araştırmış ve bu çalışmalarında cinsiyet değişkeni ile matematik başarıları arasında anlamlı bir farklılık bulamamışlardır.

Sınıf öğretmeni adayları ile okul öncesi öğretmen adaylarının birlikte cinsiyet değişkenine göre, matematiğe yönelik ön/son başarı testleri ve ön/son tutum testleri incelendiğinde; erkek ve kadın sınıf öğretmeni adayların ön/son başarı testleri ve ön/son tutum testleri arasında anlamlı bir farklılı̆ın son test ve son tutum lehine; erkek ve kadın okul öncesi öğretmen adaylarının ön/son başarı testleri arasında anlamlı bir farklılığın ise son test lehine olduğu görülmüştür. Ancak erkek ve kadın okul öncesi öğretmen adaylarının ön/son tutum testleri arasında anlamlı bir farklılığın olmadığı görülmüştür (Tablo 9). Bu duruma göre, kadın ve erkek sınıf öğretmeni adaylarının matematiğe yönelik başarı ve tutumları bakımından, etkinlik temelli işlenen laboratuvar derslerinden olumlu etkilendikleri yani, başarının artığını ve matematiğe yönelik tutumlarının olumlu yönde gelişme gösterdiği söylenebilir. Okul öncesi öğretmen adaylarının bulunduğu grupta ise, etkinlik temelli işlenen laboratuvar derslerinin kadın ve erkeklerde başarıyı artırdığı fakat matematiğe yönelik tutumlarında bir değişiklik yaratmadığı söylenebilir.

Genel olarak sınıf öğretmeni adayları ile okul öncesi öğretmen adayları arasında cinsiyet değişkenine göre öğrenilenlerin kalıcılı̆̆ı ve matematiğe yönelik tutumları açısından $(P>0.05)$ anlamlı bir farklılı̆ın meydana gelmediği görülmektedir (Tablo 10). Bu sonuca göre, öğretmen adaylarının anlama ve unutmama bakımından kazandıkları bilgi düzeylerini korudukları söylenebilir.

\section{5. Öneriler}

Yapılan bu araştırmanın sonuçlarına ilişkin olarak aşağıdaki öneriler verilebilir:

Uygulamaya Dönük Öneriler: Matematik eğitiminde (özellikle ilköğretimde), etkinlik temelli laboratuvar uygulamalarını kapsayan müfredatlar gözden geçirilebilir. Seçmeli dahi olsa bu konuda ders açılabilir. Bu çalışmaların yapılması sürecinde üniversitelerin ilgili bölümleri ile işbirliği yapılabilir. Okullarda matematik eğitimi laboratuvarların oluşturulmasında rehberlik yapılabilir.

Araştırmaya Dönük Öneriler: Öğretmen adayları üzerinde yapılan bu çalışmanın değişik sosyoekonomik ve sosyokültürel yapıya sahip bölgelerde özellikle ilkokul ve ortaokullarda çalışması yapılabilir. Bu çalışma farklı araştırma teknikleri kullanılarak yapılabilir. Ayrıca bu çalışma sadece bir dönemi kapsamaktadır. Daha uzun dönemleri kapsayan derinlemesine deneysel çalışmalar yapılabilir.

\section{Kaynakça}

Agwagah, U. N. V. (1997). Laboratory approach to mathematics/instruction: A situation report on Nigerian Secondary schools in the 1990s. J. Liberal Studies 5(2), 116-124.

Arslan, B. (2003). Bilgisayar destekli eğitime tabi tutulan ortaöğretim öğrencileriyle bu süreçte eğitici olarak rol alan öğretmenlerin Bde'ye ilişkin görüşleri. The Turkish Online Journal Of Educational Technology, 2(4), 67-75.

Baki, A., Kösa, T. \& Berigel, M. (2007). Bilgisayar destekli materyal kullanımının öğrencilerin matematik tutumlarına etkisi. The Proceedings of 7th International Educational Technology Conference, Near East University, North Cyprus.

Bedir, D. (2005). Bilgisayar destekli matematik öğretiminin ilköğretimde geometri öğretiminde yeri ve öğrenci başarısı üzerindeki etkisi. Yayımlanmamış yüksek lisans tezi, Dokuz Eylül Üniversitesi Eğitim Bilimleri Enstitüsü, İzmir.

Birgin, O. \& Tutak, T. (2006). Geometri öğretiminde bilgisayar destekli öğretimin öğrenci başarısına etkisi. IETC 2008, Eskişehir, Türkiye.

Brand, R. (1990). On learning styles: A conversatıon with pat guild. Educatıonal Leadershıp, 48(2), 10. 
Bozkurt, A. \& Akalın, S. (2010). Matematik öğretiminde materyal geliştirmenin ve kullanımının yeri, önemi ve bu konuda öğretmenin rolü. Dumlupınar Üniversitesi Sosyal Bilimler Dergisi, 27, 47-56.

Duatepe, A. \& Ubuz, B. (2003). Drama temelli geometri ders planının geliştirilmesi ve uygulanması. www.tiyatrom.com/egitimde drama15.htm

Ekinöz, í. \& Şengül, S. (2007). Permütasyon ve olasılık konusunun öğretiminde canlandırma kullanılmasının öğrenci başarısına ve hatırlama düzeyine etkisi. Kastamonu Eğitim Dergisi, 15(1), 251-258.

Ersoy, Y. (2006). İlköğretim matematik öğretim programındaki yenilikler-I: Amaç, içerik ve kazanımlar, Illköğretim Online, 5(1), 30-44.

Gürbüz, R. (2007). Olasılık konusunda geliştirilen materyallere dayalı öğretime ilişkin öğretmen ve öğrenci görüşleri. Kastamonu Eğitim Dergisi, 15(1), 259-27.

Güven, B. \& Karataş i. (2005). Dinamik geometri yazılımı cabri ile geometri öğrenme: öğrenci görüşleri. The Turkish Online Journal Of Educational Technology, 2(2), 67-78.

James, O. O. (2016). Effectiveness of Teaching mathematics using mathematics laboratory on students mathematical achievements in tertiary institutions. Journal of Pristine, 12(1), 151-160.

Igbokwe D. I. (2000). Dominant factors and error types inhibiting the understanding of mathematics. 41st Annual Conference Proceedings of Stan, 242-249.

İnan, C. (2006). Matematik öğretiminde materyal geliştirme ve kullanma. Ziya Gökalp Eğitim Fakültesi Dergisi, 1(7), 47-56.

İnan, C. \& Erkuş, S. (2017). Geliştirilen sayı şeridi materyalinin ilkokul 4. sınıf öğrencilerinin matematik başarıları ve tutumlarına etkisinin incelenmesi. Electronic Turkish Studies, 12(35).

Karasar, N. (2000). Bilimsel araştırma yöntemleri. (10. Baskı) Ankara: Nobel Yayın.

Kayhan, M. (2006). Somut araçlar kullanımının matematiksel sözel problem çözümündeki etkisi. XV. Ulusal Eğitim Bilimleri Kongresi, Muğla.

Kellner, D. (2002). Yeni teknolojiler/yeni okuryazarlıklar: yeni bin yılda eğitimin yeniden yapılandırılması (çeviri: Ayşe Taşkent), Kuram ve Uygulamada Eğitim Bilimleri, 105-132.

Maschietto M. \& Trouche L. (2010). Mathematics learning and tools from theoretical, historical and practical points of view: the productive notion of mathematics laboratories, ZDM Mathematics Education, 42, 33-47.

Matthews, G. (1984). Learning and teaching mathematical skills (Ed: Fontans; D.). The education of the young child. Basıl Blackwell Publisher.

Noss, R. \& Baki, A. (1996). Liberating school mathematics from procedural view. Journal Of Education Hacettepe University. 12, 179-182.

Ogunkunle, R. A. (2000): Teaching of mathematics in schools. The laboratory approach. The Nigeria Teacher Today, $8(1,2): 180-184$.

Okigbo, E. C. \& Osuafor, A. M. (2008). Effect of using mathematics laboratory in teaching mathematics on the achievement of mathematics students. Educational Research and Review. 3 (8), 257-261.

Okonkwo, C. (1997): Effect of tangram puzzle game on students' performance in mathematics. In G.A. Badmus and C. O. Ocho (Eds). Science mathematics and technology education in Nigeria, Lagos: Everlead press.

Özahisha, U. \& Öcal, R. (2004). Ilköğretim 5. sınıf öğrencileri için geometri ve matematik uygulaması. 16. Ulusal Fen Bilimleri ve Matematik Eğitim Kongresi. İstanbul.

Özahisha, U. \& Öcal, R. (2004). Analitik geometri derslerinde çalışma yaprağı kullanımı. 6. Ulusal Fen Bilimleri ve Matematik Eğitim Kongresi. İstanbul.

Pesen, C. (2005). Yeni yapılandırmacı öğrenme yaklaşımına göre yeni ilköğretim programlarının değerlendirilmesi. Kayseri Üniversitesi Yeni İlköğretim Programlarının Değerlendirilmesi Sempozyumu. Kayseri.

Santos T., M. (1996). Instructional qualities of successful mathematıcal problem solving class. Internatıonal Jurnal of Mathematıcal Educatıon in Science and Technology. 29(5), 631-646. 
Srinivasa, N. (1978): A laboratory for teaching mathematics. JSTAN 9(1) 22-24.

Tabuk, M. (2003). Ilköğretim 7. sınıflarda "Çember, daire ve silindir" konusunun öğretiminde bilgisayar destekli öğretimin başarıya etkisi. Yayımlanmamış yüksek lisans tezi, Marmara Üniversitesi Eğitim Bilimleri Enstitüsü, istanbul.

Thompson, F. M. (1994). Hands on math: ready to use games and activities for grades. The Center For Applied Research In Education West Nyack, NY 10994.

Umay, A. (1996). Matematik eğitimi ve ölçülmesi. Hacettepe Üniversitesi Eğitim Fakültesi Dergisi, 12, 145-149.

Verschaffel, L., De Corte, E., Lasure, S., Van Vaerenbergh, G., Bogaerts, H. \& Ratinckx, E. (1999). Learning to solve mathematıcal application problems : A desing experiment with fifth graders. Mathematıcal Thinking. 1(3).195-229.

Yenilmez, K. (2010). Ortaöğretim öğrencilerinin matematik dersine yönelik umutsuzluk düzeyleri. Hacettepe Üniversitesi Eğitim Fakültesi Dergisi, 38, 307-317. 